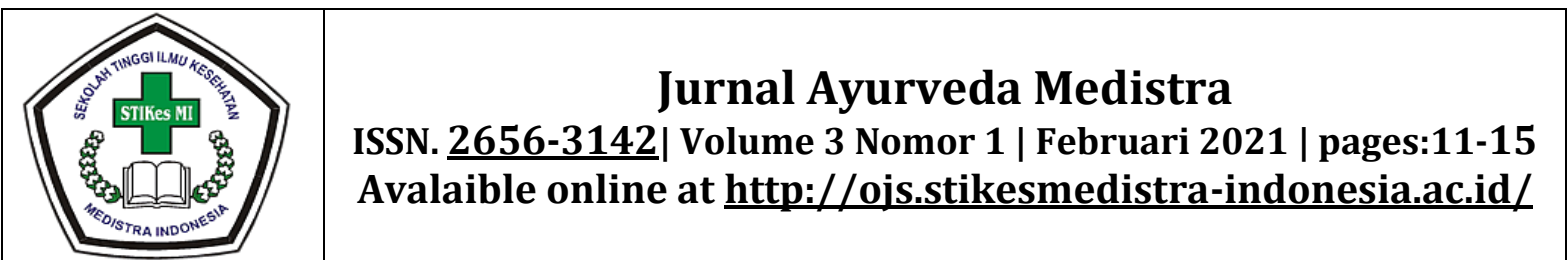

\title{
EFEKTIFITAS AROMATERAPI DAN PENDAMPING PERSALINAN TERHADAP NYERI PERSALINAN
}

\author{
Yocki Yuanti ${ }^{1 *}$, Cindy Ria Aprilia Putri ${ }^{2}$ \\ ${ }^{1 * P r o d i}$ Profesi Bidan STIKes Mitra RIA Husada Jakarta, yockiyuanti@gmail.com , 08159224848 \\ 2Prodi D-III Kebidanan STIKes Mitra RIA Husada Jakarta, cindyriaapriliaputri@gmail.com , 082125929050
}

\begin{abstract}
Abstrak
Nyeri merupakan hal yang fisiologis pada proses persalinan namun dapat menjadi pengalaman yang tidak menyenangkan dan dapat menimbulkan trauma psikologis bagi ibu bersalin. Proses pengeluaran janin pada saat persalinan ditandai dengan semakin meningkatnya intensitas dan frekwensi kontraksi uterus, yang menimbulkan rasa nyeri secara terus menerus. $90 \%$ persalinan menunjukkan nyeri pada skala berat. Tujuan penelitian ini adalah untuk menjelaskan kontribusi pemberian aromaterapi terhadap nyeri persalinan dengan pendamping persalinan sebagai variabel perancu. Desain penelitian adalah non experiment dengan pendekatan studi cross sectional. Populasinya adalah seluruh ibu yang bersalin di Puskesmas Nanggung pada tanggal 24 Februari - 14 Maret 2020. Teknik pengambilan sampel adalah accidental sampling sebanyak 40 orang. Data dianalisis menggunakan uji Chi Square dan Regresi Logistik Berganda dengan model faktor resiko. Hasil penelitian menunjukan ibu bersalin yang mengalami nyeri persalinan ringan sebanyak $65 \%$. Pemberian aromaterapi memiliki kontribusi yang signifikan terhadap nyeri persalinan pada ibu bersalin ( $p$-value 0,014$)$ dengan OR 6,768, sedangkan pendamping persalinan tidak memiliki kontribusi yang signifikan terhadap nyeri persalinan pada ibu bersalin ( $p$-value 0,127 ). Pemberian aromaterapi pada saat persalinan sangat dianjurkan dilakukan guna mengendalikan rasa nyeri yang ditimbulkan akibat proses persalinan dan penting bagi bidan mendukung ibu bersalin mengelola pengalaman melahirkan yang aman dan nyaman, minim trauma baik psikologis maupun fisiologis.
\end{abstract}

Kata kunci: Aromaterapi, Nyeri Persalinan, Pendamping Persalinan

\begin{abstract}
Pain is physiological in labor but can be an unpleasant experience and can cause psychological trauma for the mother. The process of expulsion of the fetus at delivery is characterized by the increasing intensity and frequency of uterine contractions, which cause continuous pain. $90 \%$ of deliveries show pain on a weight scale. The purpose of this study was to explain the contribution of presenting aromatherapy to labor pain with the accompanying labor variable. The research design was non-experimental with a cross sectional study approach. The population was all mothers who gave birth at the Nanggung Public Health Center on 24 February - 14 March 2020. The sampling technique was accidental sampling of 40 people. Data using Chi Square test and Multiple Logistic Regression with risk factor analysis model. The results showed that $65 \%$ of the mothers who experienced mild labor pain were in labor. The provision of aromatherapy had a significant contribution to labor pain in laboring mothers ( $p$-value 0.014) with an OR of 6.768, while delivery companions did not have a significant contribution to labor pain in laboring mothers ( $p$-value 0.127 ). The provision of aromatherapy during childbirth is highly recommended to manage the pain caused by the delivery process and it is important for midwives to support mothers who give birth in managing a safe and comfortable birth experience, minimal trauma both psychological and physiological.
\end{abstract}

Keywords: Aromatherapy, Pain Labor, Companion Labor 


\section{PENDAHULUAN}

Nyeri merupakan pengalaman sensoris dan emosional yang sangat tidak menyenangkan. Nyeri pada saat persalinan disebabkan karena adanya kontaksi uterus, dilatasi serviks dan regangan otot dasar panggul. ${ }^{1}$ Nyeri persalinan dapat meningkatkan kecemasan pada ibu bersalin. Kecemasan selama persalinan mengaktifkan sistem saraf simpatis dan memperluas sekresi hormonal seperti adrenalin, noradrenalin, dan kortisol, yang dapat meningkatkan rasa nyeri persalinan dan mempengaruhi lamanya proses persalinan. ${ }^{2}$ Berdasarkan data WHO tahun 2015 didapatkan bahwa partus lama rata-rata di dunia menyebabkan kematian ibu sebesar $8 \%$ dan di Indonesia sebesar 9\%. Partus lama dapat dipengaruhi oleh kondisi psikologis ibu yang meliputi persepsi ibu pada rasa nyeri saat persalinan. ${ }^{3}$ Oleh karena itu manajemen nyeri pada proses persalinan sangat penting.

Pendekatan farmakologis dan nonfarmakologis adalah dua metode yang lazim digunakan saat ini untuk mengurangi rasa nyeri persalinan. Dalam ilmu kebidanan saat ini, pendekatan non-farmakologis seperti teknik relaksasi, akupunktur, akupresur, terapi pijat, aromaterapi merupakan metode yang sering digunakan dalam persalinan karena terbukti efektif, efisien, penggunaannya mudah dan berisiko rendah. ${ }^{4}$

Aromaterapi efektif dalam mengurangi nyeri dan durasi persalinan, dan umumnya aman bagi ibu. ${ }^{5}$ Ahli aromaterapi menggunakan minyak esensial untuk merangsang dan menyeimbangkan kadar hormon, serta mengurangi stres. Diperkirakan bahwa menggunakan minyak esensial selama persalinan dapat membantu ibu hamil untuk rileks, juga meningkatkan kadar hormon oksitosin. ${ }^{6}$

Studi lain menunjukkan bahwa ibu yang didampingi seorang sahabat atau keluarga dekat (khususnya suami) selama proses persalinan berlangsung, memiliki risiko mengalami komplikasi yang memerlukan tindakan medis lebih kecil daripada mereka yang tanpa pendampingan. Dukungan yang terus-menerus dari seorang pendamping persalinan dapat memberikan rasa nyaman, semangat, meningkatkan rasa percaya diri dan mengurangi kecemasan. ${ }^{7}$ Oleh karena itu, tujuan penelitian ini untuk mengetahui efektitivas aromaterapi dan pendamping persalinan dalam mengatasi rasa nyeri persalinan.

\section{METODE PENELITIAN}

Penelitian ini merupakan penelitian analitik kuantitatif dengan desain Non experiment dan pendekatan studi cross sectional.

\section{Metode Pengumpulan Data}

Metode pengumpulan data menggunakan metode observasi, sedangkan populasi dalam penelitian ini adalah seluruh ibu yang bersalin di Puskesmas Kecamatan Nanggung Bogor pada tanggal 24 Februari - 14 Maret 2020. Teknik pengambilan sampel menggunakan teknik accidental sampling, Jumlah sampel 40 orang. Data kemudian diolah menggunakan uji Chi Square dan Regresi Logistik Berganda dengan model faktor resiko.

\section{HASIL DAN PEMBAHASAN}

Distribusi frekwensi rasa nyeri dalam persalinan meliputi penggunaan aromaterapi dan pendamping persalinan dapat dilihat dalam tabel 1.

Tabel 1

Distribusi Frekwensi Nyeri Persalinan, Pemberian Aromaterapi, dan Pendamping Persalinan pada Ibu Bersalin

\begin{tabular}{clcc}
\hline $\mathbf{N}$ & \multicolumn{1}{c}{ Variabel } & Jumlah & $\%$ \\
$\mathbf{0}$ & \multicolumn{3}{c}{} \\
\hline $\mathbf{1}$ & \multicolumn{2}{c}{ Rasa Nyeri Persalinan Kala I } \\
& Nyeri Ringan & 26 & 65 \\
& Nyeri Berat & 14 & 35 \\
$\mathbf{2}$ & Pemberian Aromaterapi & \\
& Ya & 27 & 67,5 \\
& Tidak & 13 & 32,5 \\
$\mathbf{3}$ & Pendamping Persalinan & \\
& Didampingi & 31 & 77,5 \\
& Tidak didampingi & 9 & 22,5 \\
\hline
\end{tabular}

Tabel 1 menunjukkan bahwa dari 40 responden, ibu yang mengalami nyeri ringan sebanyak 26 responden $(65 \%)$, responden yang diberikan aromaterapi sebanyak 27 responden $(67,5 \%)$, sedangkan responden didampingi pada saat persalinan sebanyak 31 responden $(77,5 \%)$. 
Tabel 2

Gambaran Nyeri Persalinan berdasarkan

Pemberian Aromaterapi dan Pendamping Persalinan pada Ibu Bersalin

\begin{tabular}{|c|c|c|c|}
\hline $\begin{array}{l}\mathbf{N} \\
\mathbf{0}\end{array}$ & Variabel & P Value & $\begin{array}{c}\text { OR } \\
(95 \% \\
\text { CI })\end{array}$ \\
\hline 1 & Pemberian Aromaterapi & 0,014 & 6,768 \\
\hline 2 & Pendamping Persalinan & 0,127 & 3,966 \\
\hline
\end{tabular}

Tabel 2 di atas menunjukan bahwa pada kelompok ibu bersalin dengan nyeri persalinan ringan ada sebanyak $76,9 \%$ yang diberikan aromaterapi sedangkan yang tidak diberikan aromaterapi hanya ada $23,1 \%$ dan dengan $p$ value 0,008 yang berarti pemberian aromaterapi berkontribusi secara signifikan terhadap nyeri persalinan, dimana diberikan aromaterapi memiliki peluang mengalami nyeri persalinan ringan sebanyak 8,3 kali lebih tinggi dibanding dengan ibu yang melahirkan tidak diberikan aromaterapi. Diketahui juga pada ibu yang didampingi pada saat persalinan ada sebanyak $88,5 \%$ yang mengalami nyeri persalinan ringan, kelompok ibu yang tidak didampingi ada sebanyak $11,5 \%$, dengan $p$-value 0,062 maka pendamping persalinan tidak berkontribusi terhadap terjadinya nyeri persalinan.

Tabel 3

Model Awal Analisis Multivariat

\begin{tabular}{ccc}
\hline $\mathbf{N}$ & Variabel & P Value \\
$\mathbf{0}$ & & \\
\hline 1 & Pemberian Aromaterapi & 0,005 \\
2 & Pendamping Persalinan & 0,032 \\
\hline
\end{tabular}

Dalam analisis multivariat pada pemodelan awal, pemberian aromaterapi dan pendamping persalinan masuk dalam pemodelan ( $p$ value $<$ $0,25)$, kemudian dilakukan uji interaksi, dengan hasil akhir sebagaimana diperlihatkan dalam tabel 4.

Tabel 4

Model Akhir Analisis Multivariat

\begin{tabular}{|c|c|c|c|c|c|c|c|}
\hline \multirow{3}{*}{$\begin{array}{l}\mathbf{N} \\
\mathbf{0}\end{array}$} & \multirow{3}{*}{ Variabel } & \multicolumn{4}{|c|}{ Nyeri Persalinan } & \multirow{3}{*}{$\begin{array}{c}\text { OR } \\
(95 \% \\
\text { Cl) } \\
\end{array}$} & \multirow{3}{*}{$\begin{array}{c}\text { P } \\
\text { Value }\end{array}$} \\
\hline & & \multicolumn{2}{|c|}{ Ringan } & \multicolumn{2}{|c|}{ Berat } & & \\
\hline & & $\mathbf{N}$ & $\%$ & $\mathbf{N}$ & $\%$ & & \\
\hline \multirow[t]{3}{*}{1} & Pemberian & Arom & aterap & & & \multirow{3}{*}{8,333} & \multirow{3}{*}{0,008} \\
\hline & Ya & 20 & 76,9 & 4 & 60 & & \\
\hline & Tidak & 6 & 23,1 & 10 & 71,4 & & \\
\hline \multirow[t]{3}{*}{2} & Penda & $\mathrm{Pe}$ & salinar & & & \multirow{3}{*}{5,750} & \multirow{3}{*}{0,062} \\
\hline & Didampingi & 23 & 88,5 & 8 & 57,1 & & \\
\hline & $\begin{array}{l}\text { Tdk } \\
\text { Didampingi }\end{array}$ & 3 & 11,5 & 6 & 42,9 & & \\
\hline
\end{tabular}

Tabel 4 menunjukan hasil analisis multivariat yaitu pada kelompok ibu yang diberikan aromaterapi berpeluang mengalami nyeri persalinan ringan 6,7 kali lebih besar dibanding kelompok ibu yang tidak diberikan aromaterapi. Selain itu, diketahui juga tidak ada interaksi antara pemberian aromaterapi dengan pendamping persalinan terhadap rasa nyeri persalinan pada ibu bersalin.

Nyeri persalinan merupakan hal yang fisiologis dan muncul karena kontraksi otot rahim yang menyebabkan dilatasi dan penipisan serviks serta iskemia rahim akibat kontraksi arteri miometrium, regangan otot dasar panggul. Nyeri ini timbul pada saat kala I dan mendekati kala II terlokalisir di daerah fundus uteri, vagina, rektum dan perineum, sekitar anus dan disebabkan peregangan struktus jalan lahir bagian bawah akibat penurunan bagian terbawah janin, serta kondisi psikologi yang diakibatkan oleh rasa cemas dan takut. ${ }^{3,2}$

Banyak berbagai jenis analgesia dan bentuk manajemen nyeri dalam persalinan yang dapat dipilih oleh seorang ibu bersalin. Merupakan tanggungjawab bidan untuk memastikan kliennya (ibu bersalin) memahami dirinya, mengenali rasa nyeri yang timbul akibat fisiologi persalinan, bagaimana mengatasi rasa nyeri tersebut dan memanaj rasa nyeri tersebut menjadi sesuatu yang bermakna dalam proses kelahiran bayinya. ${ }^{2}$

Dahulu secara tradisional bidan menggubakan sentuhan untuk mengurangi rasa nyeri persalinan, namun seiring perkembangan saat ini banyak ibu bersalin memilih terapi komplementer sebagai kendali diri dalam pengalamannya melahirkan menjadi nyaman dan menikmati semua proses kemajuannya. Terapi komplementer yang lazim digunakan adalah pijat, aromaterapi, refleksologi, akupunktur akupresur, shiatsu bahkan ada juga yang menggunakan hypnoterapi dan herbal. ${ }^{6}$

Pemberian aromaterapi dan pendampingan pada ibu bersalin merupakan metode non farmakologis yang sering diterapkan dalam manajemen nyeri sebagai teknik pain relief. Aromaterapi dapat membantu mengurangi nyeri dan ketidaknyamanan persalinan. Minyak atsiri dikenal karena manfaatnya dalam mengatasi infeksi, meningkatkan sistem imun dan membantu menghilangkan rasa nyeri secara alami. Efek ini disebabkan oleh aktivasi pusat otak yang lebih tinggi. Bahan kimia minyak atsiri dapat menstimulasi keluarnya hormon endorpin dan serotonin. ${ }^{1}$

Hilda melaporkan hasil penelitiannya yaitu adanya penurunan intensitas nyeri pada 
sekelompok ibu bersalin di Puskesmas yang diberikan aromaterapi lavender. ${ }^{8}$ Manfaat dari aromaterapi Lavender yaitu memberi kenyamanan, pereda nyeri, menenangkan, serta sebagai analgetik sehingga dapat mengurangi nyeri pada saat proses persalinan. Penelitian ini menunjukkan adanya kontribusi positif pemberian aromaterapi terhadap nyeri persalinan.

Kehadiran seorang pendamping persalinan akan memberikan dukungan kepada ibu bersalin sehingga dapat mempermudah proses persalinan dan melahirkan, memberikan rasa nyaman dan mengurangi kecemasan. ${ }^{9}$ Pada penelitian ini kehadiran pendamping persalinan tidak memberikan kontribusi positif terhadap nyeri persalinan.

Penelitian ini tidak sesuai dengan hasil penelitian yang dilakukan oleh Megan,et.al pada tahun 2019 yang menemukan bahwa ibu yang ditemani oleh suaminya, anggota keluarga atau seorang profesional yang dikehendaki mengatakan lebih percaya diri, nyaman dan persalinan pun berlangsung lancar sehingga dapat mengurangi rasa nyeri persalinan yang dirasakan. ${ }^{10}$

Hal ini dikarenakan pendamping persalinan yang diharapkan ibu bersalin adalah seseorang yang dapat memberikan informasi mengenai rasa nyeri dan hal-hal yang dapat dilakukan untuk mengurangi rasa nyeri. Adanya kedekatan atau bonding akan menimbulkan perasaan nyaman. Pendamping persalinan bisa suami, keluarga atau orang terdekat dari ibu bersalin, namun bisa juga seorang profesional.

\section{SIMPULAN DAN SARAN}

\section{Simpulan}

Hasil penelitian ini dapat disimpulkan bahwa sebagian ibu bersalin mengalami nyeri persalinan ringan menggunakan aromaterapi sebagai upaya untuk mengurangi rasa nyeri dan didampingi oleh suami atau keluarga pada saat proses persalinan berlangsung. Namun pendamping persalinan tidak ada kontribusi yang signifikan terhadap nyeri persalinan. Hal ini dikarenakan kehadiran seorang pendamping persalinan seharusnya orang yang diharapkan kehadirannya dan dapat memberikan support system, memahami ibu sehingga meningkatkan rasa percaya diri dalam mengelola rasa nyeri sebagai suatu kekuatan yang nyaman dalam proses kelahiran bayi.

\section{Saran}

Pemberian aromaterapi pada ibu bersalin secara rutin terutama pada persalinan kala I dianjurkan dalam manajemen nyeri persalinan.
Demikian halnya dengan pendamping persalinan, dianjurkan dilakukan oleh orang terdekat yang diharapkan oleh ibu bersalin dan mampu memberikan rasa nyaman pada ibu bersalin sehingga meningkatkan rasa percaya diri, atau bisa juga digantikan dengan seorang profesional yang memiliki kompetensi.

\section{DAFTAR PUSTAKA}

1. Ghiasi A, Bagheri L, Haseli A. A Systematic Review on the Anxiolytic Effect of Aromatherapy during the First Stage of Labor. J caring Sci [Internet]. 2019 Mar 1 [cited 2021 Jan 23];8(1):51-60. Available from:

http://www.ncbi.nlm.nih.gov/pubmed/3091 5314

2. Prawirohardjo S. Ilmu Kebidanan. Jakarta: Bina Pustaka Sarwono Prawiroharjo; 2017.

3. Judha M dkk. Teori Pengukuran Nyeri \& Nyeri Persalinan. Yogyakarta: Nuha Medika; 2017.

4. Tabatabaeichehr M, Mortazavi H. The Effectiveness of Aromatherapy in the Management of Labor Pain and Anxiety: A Systematic Review [Internet]. Vol. 30, Ethiopian journal of health sciences. NLM (Medline); 2020 [cited 2021 Jan 23]. p. 449-58. Available from: https://pubmed.ncbi.nlm.nih.gov/3287408 8/

5. Chen SF, Wang $\mathrm{CH}$, Chan PT, Chiang HW, Hu TM, Tam KW, et al. Labour pain control by aromatherapy: A meta-analysis of randomised controlled trials. Women and Birth [Internet]. 2019 Aug 1 [cited 2021 Feb 15];32(4):327-35. Available from: https://pubmed.ncbi.nlm.nih.gov/3034402 9/

6. Ayuningtyas IF. Kebidanan Komplementer. In Yogyakarta: Pustaka Baru Press; 2019.

7. Mutmainah AU dkk. Asuhan Persalinan Normal \& Bayi Baru Lahir. In: Utami RI, editor. Samarinda: ANDI; 2017.

8. Karo HK, Karo HYK, Pramono N, Wahyuni S, Mashoedi ID, Latifah L. LAVENDER (Lavandula Angustifolia) Aromatherapy As An Alternative Treatment In Reducing Pain In Primiparous Mothers In The Active First Stage Of Labor. Belitung Nurs J. 2017 Aug;3(4):420-5.

9. Thomson G, Feeley C, Moran VH, Downe $S$, Oladapo OT. Women's experiences of 
pharmacological and non-pharmacological pain relief methods for labour and childbirth: A qualitative systematic review [Internet]. Vol. 16, Reproductive Health. BioMed Central Ltd.; 2019 [cited 2021 Jan 23]. Available from: /pmc/articles/PMC6543627/?report=abstr act

10. Ö BohrenMA T. Cochrane Library Cochrane Database of Systematic Reviews Perceptions and experiences of labour companionship: a qualitative evidence synthesis (Review). 2019 [cited 2021 Jan 23]; Available from: www.cochranelibrary.com 